\title{
PNEUMONIA IN PREGNANCY.
}

\author{
By H. C. DRURY, M.D., F.R.C.P.I.; \\ Physician to Sir Patrick Dun's Hospital, Dublin.
}

[Read in the Section of Medicine, March 3, 1905.]

Pnecmonta in pregnancy is stated to be rare. Acute lobar pneumonia "is one of the most widely extended as well as one of the most fatal diseases" (West). By far the largest proportion of cases occur within the ages which coincide with the child-bearing period of life. But although men are attacked more frequently than women in the proportion of two or three to one, it is sufficiently common in women to make it surprising to find that pneumonia as a complication of pregnancy is rare. Though I have met with a very large number of cases of pneumonia, I may consider myself fortunate in having seen three cases occurring in pregnant women. It is difficult to find records of such cases, and references by various writers on this subject are very vague and general. Grisolle collected fifteen cases (Archiv. gen. de Ied., vol. xiii., p. 291), which is the largest number I have been able to find.

In such a dangerous disease as pneumonia, which is said to account for 12.7 per cent. of all the deaths from purely medical diseases (West), one would expect that when it attacked a pregnant woman the case was wellnigh hopeless. This is, indeed, the view mostly held by writers, though they, as a rule, give but vague and indefinite reasons for their faith. Moore ("Ency. Med.," vol. ix., p. 446) considers that one reason for the greater mortality of pneumonia among women than in men is that pregnancy adds immensely to its danger. The- 
statistics of St. Bartholomew's Hospital, however, throw doubt on this supposed higher relative mortality in women. West's statisties show a percentage of 23.5 for men and 22.0 for women, and the statistics of St. Thomas's Hospital show 21.4 for men, and 16.3 for women. Grisolle's fifteen cases would tend to support the idea that pneumonia is very fatal in pregnancy, for eleven of those fifteen cases died; but West, who seems to be little influenced by general statements, preferring to depend on his own observation and accurate statistics, says: "Pneumonia but rarely arises in the course of pregnancy, but when it does it usually causes abortion, and the child is lost. The mother, howerer, frequently escapes." (P. 298.)

Pneumonia is just the class of febrile disease in which we would expect premature expulsion of the fotus, for here we have, as a rule, a high range of temperature which is rapidly attained, and may as rapidly fall; severe constitutional disturbance and great respiratory embarrassment, with probable cyanosis. Any one of these conditions we know is liable to bring about the death or premature expulsion of the fotus, but when combined they are almost certain to do so.

As in other febrile states, labour is usually rapid and easy; in fact, it is recognised by midwifery authorities that in these conditions "precipitate labour often occurs." It is necessary for the patient that there should not be undue delay, and if there is marked dyspncea, cyanosis, or symptoms of a failing heart, steps must be taken to aid and hasten the labour. The relief of abdominal pressure and the hæmorrhage consequent on labour appear to be beneficial in easing the respiration and relieving the engorgement of the right side of the heart, so that when labour has been safely accomplished, the 
patient is considerably relieved, and sleep-the thing most frequently wanting, the most difficult to obtain, and the most beneficial when it occurs-is obtained. The puerperal state should be managed precisely as in any normal case, and there is no increased risk of sepsis. The pneumonic condition must be treated as though pregnancy was not present. Stimulants will probably be required, but should be withheld if possible till the time of labour. At this time the hypodermic injection of strychnin, and the administration of digitalis or digitalin, may also be required if there are signs of heart failure, and oxygen may possibly be of some slight value when there is marked cyanosis. If there is engorgement of the right side of the heart, venesection to 20 or 30 ounces gives some relief.

The cases I have met with are briefly as follow:--

CASE I.-J. J., aged twenty-two, primipara, in seventh month of pregnancy, came under observation on the sixth day of disease, and was found to have pneumonia of the whole upper lobe of the right lung. She was an anæmic girl, and appeared desperately ill, with orthopnoea and an expression of intense anxiety and suffering, but no cyanosis; the pulse 128 , temperature $103.4^{\circ} \mathrm{F}$. and respiration 28 in the morning, and 40 in the evening. During the night of the seventh day there was an attempt at-or pseudocrisis, the temperature falling $3.4^{\circ}$, but she was found to have developed pneumonia of the left upper lobe. The next evening the temperature had reached $103.6^{\circ}$, and premature labour came on during the night; it was easy, rapid, and normal ; the child was dead, but apparently quite recently so. The morning after labour-eighth day-the temperature fell to $98.4^{\circ}$, but soon rose again, and came finally down to normal on the fourteenth day. Convalescence was now rapid and uninterrupted. After delivery, though still suffering from active pneumonia of the left apex and unresolved pneumonia of the right apex, she expressed herself as "feeling grand." Her pulse never rose above 102, her breathing was easy and not distressed, and she slept most of the day and night. 
CASE II.-L. O'C., 3-para, in seventh month, aged thirty-two; labour in both previous confinements said to be very short and easy. She was admitted to the hospital on the fourth day of illness. There was then well-marked pneumonia of right base, and fine crepitation at left base; temperature $103^{\circ}$, pulse 120 , respiration 24 . She was very sick, but did not appear in a dangerous condition. By the sixth day there was well-marked pneumonia of left base, and that night there was a pseudo-crisis, the temperature falling to $98.2^{\circ}$, but other symptoms not abating. On the night of the seventh day she was confined. The labour. was easy and very rapid; there was practically no pain. The child was alive, obviously premature, but only lived eleven hours. Patient appeared very easy when seen next morning, and she slept plentifully. Genuine crisis occurred on the night of the eighth day-i.e., seven days after the pneumonia attacked the left base. She made a rapid and uninterrupted recovery, and was up for an hour on the fifteenth day.

CASE III.-E. N., aged twenty-eight, 6-para, eight months pregnant. Admitted on fifth day of illness, and found to be suffering from pneumonia of lower lobe of right lung. Condition good ; temperature moderate, pulse quiet and of good quality ; respirations hurried, but not distressing. These conditions were maintained, and she slept fairly well. Movements of the child were felt on the seventh day. Early on the morning of the eighth day labour came on; it was easy, brief, and quite normal. The child was premature, and just alive when born, but died immediately after. When seen four hours after, the patient was comfortable and easy. Next morning she was noticed to speak rather strangely about her home, and worning instructions were given to watch her closely. Very soon she became wildly delirious, and remained so for six days. Whether this was ordinary febrile or post-febrile delirium, or mania of the puerperal type, it is difficult to say. The temperature, which hart rapidly fallen to normal on the ninth day, ran up on the three successive evenings, falling each morning to normal or subnormal, but from the thirteenth day it remained normal. This latter febrile condition was evidently in some way due to the disturbance of the delirium, as the pneumonic lung began at once and continued to resolve after the ninth day, and the uterine 
conditions were quite satisfactory. After the week of delirium she seemed quite well; after another week she was allowed up, and left perfectly well.

These three cases do not give one sufficient grounds for drawing important conclusions; the fallacy of doing so is seen in the fact that all three were in the seventh or eighth month of pregnancy; yet no one would surely suppose that this was the likely period for a woman to be attacked. We have seen inferences drawn, however, from just as absurd bases. Yet there are one or two points illustrated which tend to bear out what I said in introduction. First, it is not necessarily such a deadly complication as some writers would have us believe. Two were cases of double pneumonia-a sufficiently grave condition in itself--but one of these was, in addition, double apical pneumonia. Yet all three, though profoundly ill, never appeared in immediate danger, and their recovery bears out West's remark that "the mother frequently escapes."

In all, premature delivery occurred, which appears to be the usual course of events. Delivery having been safely accomplished, the patient's condition appeared to be materially improved, all the symptoms, temperature, pulse, and respiration being lower. Delivery was rapid and easy in each case, which appears, for some reason, to be the rule in labour during febrile conditions, perhaps due to the softening and relaxation of the genital passages as a result of the high temperature. There was no additional trouble in the management of the puerperal state, the lochia were normal, and had no special tendency to become septic; the breasts gave no trouble, as the secretion was to a large extent checked by the fever.

The three children succumbed, but, though premature, they were alive up to the time of birth, and if they had 
been nearer maturity might have survived, one having lived eleven hours.

DR. Ninian Falkiner said he considered the subject a most important one, and congratulated Dr. Drury on his successful treatment. He read the report of a case of his own, which appeared in the British Medical Journal of March 2nd, 1899. He also gave some statistics of the mortality in those cases. In England in 1901 the cases of death from pneumonia in pregnancy or childbearing showed a percentage of 3.42 of all the deaths of women associated with these conditions. In 1902 the percentage was 6.46, and in Ireland in 1902 it was 1.52 per cent. of all deaths definitely returned as either caused by or associated with pregnancy or childbearing.

Dr. Dax said that, with reference to the question of pneumonia in pregnancy, his experience was that women who were young did not die. He had never had to use forceps in a case with fever. The child's chances of survival were very slight. Cases of abortion gave more trouble or cases in which the foetus was not viable. He doubted whether a woman who was pregnant was less liable to get pneumonia than a non-pregnant woman. There was no reason why such patients should get cyanosis as long as one lung was free. What one had to treat was the fever and want of sleep-in other words, the nervous disturbance. There was also a certain amount of hypertrophy of the heart, and it was the heart which usually failed. In these cases no internal examination should be done, and the case should not be interfered with. One thing which made pneumonia peculiarly liable to cause abortion was the high temperature. He thought it was important to have got these three cases together as emphasising the point that pneumonia was not such a dangerous complication of pregnancy as was usually supposed.

DR. NeILL said that delivery in these cases was usually very easy owing to the prematurity of the fotus. He had seen also several cases in the last stages of phthisis in which the delivery was perfectly easy. He had seen a case of placenta prævia occurring in a patient who had advanced phthisis. She got over it well, and had a normal child afterwards.

Dr. Moorhead said he had had one case of pneumonia in pregnancy. The patient was a primipara, aged thirty-seven, 
and about four and a half or five months pregnant. The whole of the right lung was involved. Convalescence was prolonged, and there was cyanosis from an early period and all through the fever. A perfectly healthy child was born at full term.

DR. DRURY thought that gynæcologists should pay more attention to the statistics of these cases. The tendency to abortion was not so great when the fever occurred at an early term, but in most cases, especially in the later periods, the fotus was usually not retained. 